\title{
Isolation and Characterization of a Substance which Stimulates the Formation of Akinetes in the Cyanobacterium Cylindrospermum licheniforme Kütz.
}

\author{
By TAKAYASU HIROSAWA* AND C. PETER WOLK† \\ MSU-DOE Plant Research Laboratory, Michigan State University, \\ East Lansing, Michigan 48824, U.S.A.
}

(Received 18 November 1978)

\begin{abstract}
A substance which at low concentration (less than $0.3 \mu \mathrm{M}$ ) stimulated the formation of akinetes in Cylindrospermum licheniforme Kütz. was purified from the centrifugal supernatant fluid of sporulating cultures. High resolution mass spectrometry showed that the chemical formula of the substance is $\mathrm{C}_{7} \mathrm{H}_{5} \mathrm{OSN}$. Other peaks of high intensity found at $m / e$ values of 123 and 96 in the mass spectrum were produced by loss of $\mathrm{CO}$ from the molecular ion, and by additional loss of HCN. Proton nuclear magnetic resonance spectroscopy of the substance showed a complex of peaks in the region of $\delta=7 \cdot 19$ to $7 \cdot 29$ p.p.m. Peaks in the infrared absorption spectrum were attributable to methylene C-H bonds and to $\mathrm{C}=\mathrm{S}$ and cyclic $-\mathrm{CO}-\mathrm{NH}-$ groups. The most probable structure consistent with the above findings embodies two fused, five-membered rings, one of which is a lactam and the other of which has a thioketone group.
\end{abstract}

\section{INTRODUCTION}

The attractive, but as yet not thoroughly validated, concept that sporulation of Bacillus is controlled by catabolic repression (Schaeffer et al., 1965; Sonenshein \& Campbell, 1978) was proposed in part on the basis of the observation that $B$. subtilis can sporulate during exponential growth, with the ratio of spores to total cells depending on the composition of the medium. As is shown in the preceding paper, the cyanobacterium (blue-green alga) Cylindrospermum licheniforme can also sporulate while growing exponentially, with the ratio of spores to total cells depending on the medium used for growth (see Fig. 1 and Table 5 of Hirosawa \& Wolk, 1979). However, sporulation of the latter organism is controlled, at least in part, by a positive effector (Fisher \& Wolk, 1976). We have developed a procedure for purifying the active substance to homogeneity. Characterization of certain of its physical properties has permitted extensive but incomplete definition of its structure.

\section{METHODS}

Organism and methods of culture. Stock cultures of Cylindrospermum licheniforme Kütz. ATCC 29412 were grown and bioassays of the sporulation-stimulatory substance which it produces were performed as described by Hirosawa \& Wolk (1979). The substance was purified from supernatant fluids obtained by centrifuging cultures at $17300 \mathrm{~g}$ (RC-2B centrifuge equipped with an SS-34 rotor and a continuous flow attachment; Dupont-Sorvall, Norwalk, Conn., U.S.A.). Cultures were grown in 161 phosphate-free standard sporulation medium (SSM) and were inoculated, aerated and illuminated as described for other 161 cultures (Hirosawa \& Wolk, 1979).

Gel filtration. Gel filtration was performed on a column $(2.5 \mathrm{~cm}$ i.d. $\times 40 \mathrm{~cm})$ of Sephadex G-25, fine. The

* Present address: 2-5-13 Ikeda, Kawasaki, Kanagawa, Japan.

$\dagger$ To whom requests for reprints should be sent. 
column was eluted with water at a flow rate of $0.5 \mathrm{ml} \mathrm{min}^{-1}$. The void volume was $87 \mathrm{ml}$. Twenty-four $10 \mathrm{ml}$ fractions were collected.

Sequence of operations for chemical fractionation.

(a) Extraction with methanol. Cell-free supernatants from $12 \mathrm{~d}$-old 161 batch cultures in SSM were evaporated in a Büchi rotary evaporator (Flawil, Switzerland) at $55^{\circ} \mathrm{C}$, leaving a partially oily residue. The residue was extracted three times with $800 \mathrm{ml}$ absolute methanol. The insoluble residue, removed by filtration on Whatman no. 1 filter paper, was re-extracted with an additional 500 to $600 \mathrm{ml}$ absolute methanol. The residue was denoted the methanol-insoluble fraction. The methanol-soluble material was concentrated approximately fivefold in a rotary evaporator at $35^{\circ} \mathrm{C}$. During this condensation a large amount of white material precipitated. The precipitate was removed by centrifuging $(20000 \mathrm{~g}, 20 \mathrm{~min})$ and the pellet was washed once with a small volume of absolute methanol. The combined supernatants were stored at $-20^{\circ} \mathrm{C}$ overnight. A precipitate which appeared during this cold treatment was removed by centrifuging as before. The pellet, combined with that from the previous step and dried under a current of air, was designated the methanol-precipitate fraction. The final supernatant fluid was evaporated to dryness at $35^{\circ} \mathrm{C}$ in a rotary evaporator. The dried methanol-soluble materials were redissolved in $160 \mathrm{ml}$ double-distilled water and designated the methanolic extract fraction.

(b) Charcoal-celite column fractionation. Activated charcoal (Darco G-60) and Celite 545 were cleaned by boiling for $10 \mathrm{~min}$ in $20 \%(\mathrm{v} / \mathrm{v})$ acetic acid and $6 \mathrm{M}-\mathrm{HCl}$, respectively, and were then washed extensively with (i) hot $\left(95^{\circ} \mathrm{C}\right)$ double-distilled water, (ii) $50 \%$ (v/v) glass-distilled ethanol containing $2 \%(\mathrm{v} / \mathrm{v}) \mathrm{NH}_{4} \mathrm{OH}$ and (iii) distilled water. They were dried at $120^{\circ} \mathrm{C}$ and kept at $120^{\circ} \mathrm{C}$ until used.

To minimize the loss of activity by irreversible binding to charcoal, the minimum amount of charcoal required to remove the sporulation-stimulatory substances from the culture supernatant was used. With $13 \mu \mathrm{g}$ charcoal per $\mathrm{ml}$ of the original supernatant, 82 to $85 \%$ of the original activity was removed from the supernatant, and a decrease in the absorption between 270 and $290 \mathrm{~nm}$ coincided with the loss of activity. Charcoal-celite column fractionation was performed on a glass column $(0.5 \mathrm{~cm}$ i.d. $\times 0.9 \mathrm{~cm})$ packed with a $1: 2(\mathrm{w} / \mathrm{w})$ mixture of charcoal and celite. The methanolic extract, diluted with distilled water to between 0.04 and 0.1 of the volume of the original culture supernatant so as to obtain essentially complete adsorption of the active substance, was passed through the column at a flow rate of $100 \mathrm{ml} \mathrm{h}^{-1}$. The adsorbed materials were eluted with $50 \%$ glass-distilled ethanol followed by $50 \%$ ethanol containing $2 \%$ $\mathrm{NH}_{4} \mathrm{OH}$.

(c) Paper chromatography. Chromatography paper $(20 \times 20 \mathrm{~cm}$, Whatman no. 1) was washed by descending chromatography with both propan-2-ol/formic acid/water (20:1.1:5, by vol.; solvent system I) and propan-2-ol/58\% $\mathrm{NH}_{4} \mathrm{OH} /$ water (9:1:1, by vol.; solvent system II). The paper was dried between and after the two washings. A toxic effect on the growth of $C$. licheniforme shown by the extracts from unwashed papers was completely abolished by washing. The extracts also did not show growth-stimulatory effects. Descending paper chromatography of the combined ethanolic eluates from the charcoal-celite column was then performed with solvent system II. Bands of material were located under white light or short-wave ultraviolet (u.v.) light, or by spraying with a $2 \%(\mathrm{w} / \mathrm{v})$ solution of ninhydrin in acetone acidified with $2 \mathrm{M}$-formic acid.

(d) Silica gel thin-layer chromatography. This was performed on plates coated with silica gel 60F-254 (which contains a fluorescent indicator) to a thickness of $0.25 \mathrm{~mm}$ (E. Merck, Darmstadt, W. Germany) in a solvent system (III) consisting of butan-1-ol/acetic acid/ether/water $(9: 6: 3: 1$, by vol.; Piskornik \& Bandurski, 1972). The plates were pre-washed with this solvent system.

(e) Cellulose thin-layer chromatography. This was performed in solvent system II on plates coated with a layer of cellulose $0.25 \mathrm{~mm}$ thick (Analtech, Wilmington, Del., U.S.A.) and pre-washed with solvent systems I and II.

( $f$ ) Microdistillation. Microscale vacuum distillation was performed according to a modification of the method of Roper \& Ma (1957). A methanolic solution of the sample was introduced into the lower chamber of an L-shaped glass tube. After evaporation of the solvent, the end of the tube containing the sample was immersed in mineral oil in a well of a heating block. The distillate was collected in a $U$-shaped tube which was immersed in an ethanol/dry ice bath and connected to a vacuum pump. A vacuum of 0.03 to $0.04 \mathrm{mmHg}$ (4 to $5 \mathrm{~Pa}$ ) was maintained during the distillation.

Determination of dry weight. Samples were lyophilized in tared culture tubes and then re-weighed.

Structural characterization. Mass spectroscopy was done with a CH5-direct probe mass spectrometer (Varian MAT, Bremen, W. Germany) with electron impact ion source, interfaced to a Digital Equipment Company PDP-11/40 computer. Precise mass measurements were made by the peak matching technique (Quisenberg et al., 1956), with perfluoroalkanes as a reference.

Nuclear magnetic resonance (n.m.r.) spectroscopy was done with a Bruker model WH-180S Fouriertransform spectrometer (Bruker Spectrospin, Wissenbourg, France). The samples were dissolved in $\left[{ }^{2} \mathrm{H}\right]$ acetonitrile. 
Infrared (i.r.) absorption spectroscopy was done with a Perkin-Elmer model 621 grating infrared spectrophotometer (Perkin-Elmer Corp., Norwalk, Conn., U.S.A.). A sample-containing solution in glass-distilled acetone was mixed with $\mathrm{KBr}$ in a mortar by dropwise addition of the solution to the salt. A control mixture was prepared with only acetone and $\mathrm{KBr}$. The mixtures were then evacuated overnight in a desiccator. Discs were made in an evacuable $\mathrm{KBr}$ die (Perkin-Elmer Corp.) pressed with a Carver hydraulic press (F.S. Carver, Summit, N.J., U.S.A.).

Ultraviolet absorption spectroscopy was done with a DB-G spectrophotometer (Beckman Instruments, Irvine, Calif., U.S.A.).

Chemicals. Darco G-60 activated charcoal was obtained from Sargent-Welch (Skokie, Ill., U.S.A.); Celite 545 from Fisher Scientific Co. (Pittsburgh, Pa, U.S.A.); propan-2-ol, diethyl ether, formic acid and $58 \% \mathrm{NH}_{4} \mathrm{OH}$ from Mallinckrodt (St Louis, Mo., U.S.A.); butan-1-ol from Aldrich Chemical Co. (Milwaukee, Wis., U.S.A.); and glass-distilled methanol from Burdick and Jackson Lab. (Muskegon, Mich., U.S.A.). All other chemicals were obtained from Sigma. Solvents were always redistilled before use. Structures were modelled with CPK space-filling atomic models (Schwarz/Mann, Orangeburg, N.Y., U.S.A.).

\section{RESULTS}

\section{Isolation and purification}

When the centrifugal supernatant fluid from a $12 \mathrm{~d}$-old culture in SSM was subjected to Sephadex G-25 gel filtration, material having the capacity to stimulate the formation of akinetes eluted from the column between 140 and $200 \mathrm{ml} \mathrm{(1.6} \mathrm{and} 2.3$ times the void volume, respectively) and accounted for over $90 \%$ of the sporulation-stimulatory activity of the original culture supernatant fluid, suggesting that the molecular weight of the stimulatory factor might be less than 5000 .

Bioassay of the methanol-soluble fraction derived from dried culture supernatant fluid indicated that it had 75 to $88 \%$ of the original sporulation-stimulatory activity of the culture supernatant (Table 1). Only 3 to $12 \%$ of the original activity was present either in the methanol-insoluble fraction or in the methanol-precipitate fraction (Table 1). The methanolic extract could be stored at $4{ }^{\circ} \mathrm{C}$ for several months without loss of activity, and $80 \%$ or more (see Fisher \& Wolk, 1976) of the original activity survived autoclaving at $121{ }^{\circ} \mathrm{C}$ for $20 \mathrm{~min}$. However, $94 \%$ of the activity was lost on treatment with $6 \mathrm{M}-\mathrm{HCl}$ at $110^{\circ} \mathrm{C}$ for $24 \mathrm{hr}$.

After adsorption of the active material to a column of charcoal and celite, the first and second $500 \mathrm{ml}$ of unadsorbed effluents from the column exhibited 10 to $19 \%$ of the activity of the original methanolic extract. Elution of the column with $50 \%$ ethanol removed 50 to $60 \%$ of the original activity, and an additional 24 to $28 \%$ of the original activity were eluted with $50 \%$ ethanol containing $2 \% \mathrm{NH}_{4} \mathrm{OH}$ (Table 1). The activities in the ethanolic eluate and ethanol/ammonia eluate fractions, but not in the unadsorbed fractions, increased with concentration (data not shown). Combination of the four fractions resulted in full recovery of the original activity of the methanolic extract applied to the column.

The loss of dry weight during paper chromatography (Table 1), the next step in the purification procedure, was due to irreversible binding of brown material at the origin of the paper (Fig. 1a). The chromatogram was divided into three sections (Fig. 1a), and each section was cut into small pieces and extracted with solvent system II. The results of bioassay of the extracts are shown in Table 1 . The eluates from sections 1 and 3 each exhibited between 0 and $7 \%$ and that from section 2 exhibited up to $91 \%$ (but in Table 1 substantially less) of the original activity of the ethanolic eluates.

Chromatography on thin layers of silica gel of the extract from section 2 of the paper chromatogram gave rise to five bands which were visualized against the fluorescent background by means of u.v. light (Fig. $1 b$ ). The chromatogram was divided into six sections; each was scraped from the plate and extracted three times with $50 \%$ ethanol. The extract from section 1, but excluding the solvent front, exhibited 65 to $98 \%$ of the activity of the extract applied to the plate (Table 1); the extract from section 4 exhibited 11 to $12 \%$ of the 

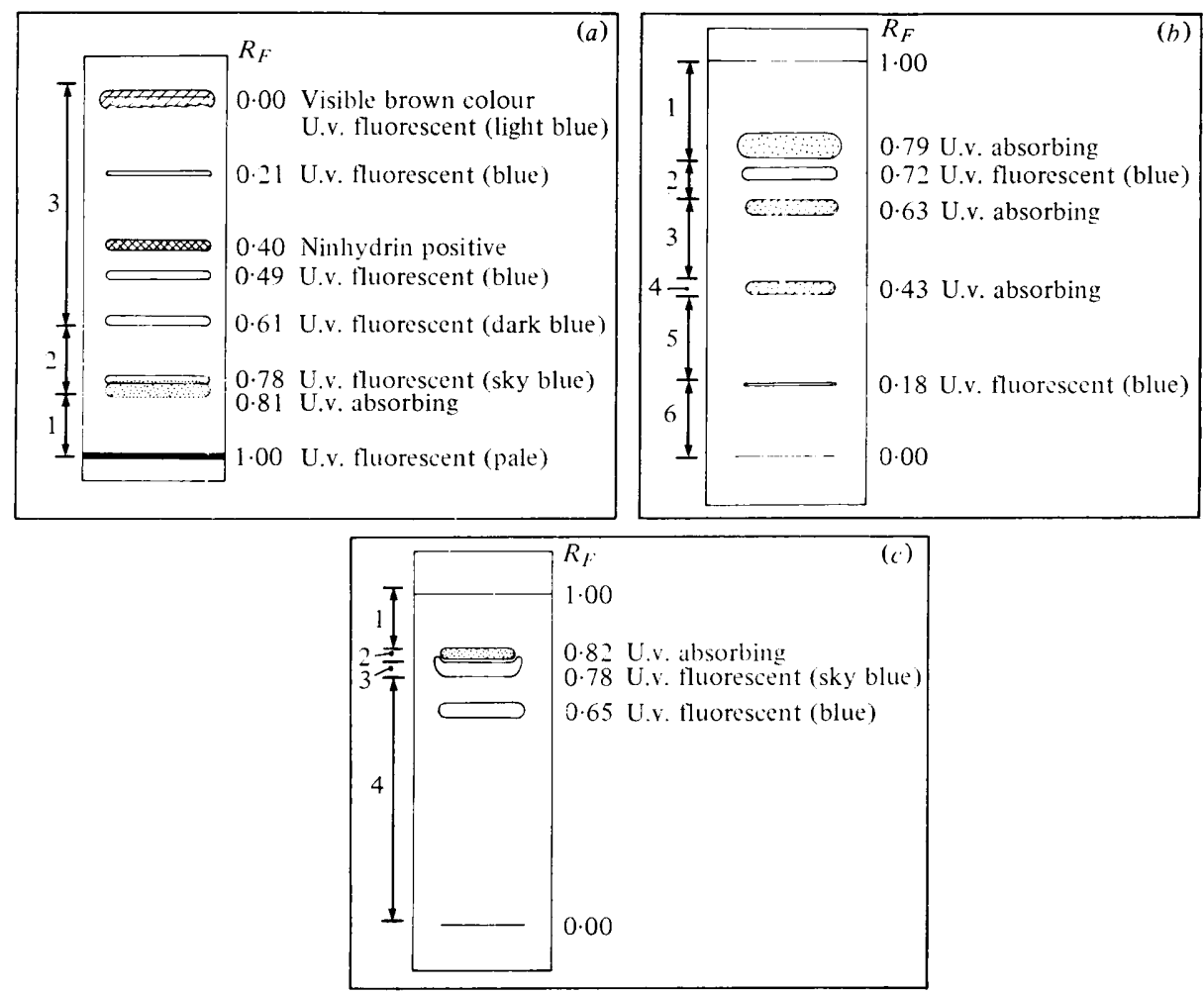

Fig. 1. Chromatographic separations. The chromatograms were cut into sections, as indicated, and each section was extracted for bioassay. The results of the bioassays are shown in Table 1 . (a) Descending paper chromatogram of the combined ethanolic eluates from a charcoal-celite column, developed with propan-2-ol $/ 58 \% \mathrm{NH}_{4} \mathrm{OH} /$ water $(9: 1: 1$, by vol.). The bands were located under u.v. light or by subsequent spraying with a solution of ninhydrin. (b) Silica gel thin-layer chromatogram of the extract from section 2 of paper chromatogram ( $a$ ), developed with butan-1-ol/ acetic acid/ether/water $(9: 6: 3: 1$, by vol.). (c) Chromatogram on a thin layer of cellulose of the extract from section 1 (but excluding the solvent front) of the silica gel thin-layer chromatogram $(b)$, developed with the same solvent system as in $(a)$.

original activity; and the extracts of the other bands exhibited low and irreproducible activity. When the extract from section 1 was dried, it contained a large amount of crystals. These crystals came from the plate itself, rather than from the extract which had been applied to the plate, and accounted for the increase in dry weight during this chromatographic step (Table 1); they had no effect on the formation of akinetes or on the growth of an assay culture.

Chromatography on thin layers of cellulose of the active extract from section 1 of a silica gel chromatogram gave rise to three bands of material (Fig. 1c). The chromatogram was divided into four sections; each was scraped from the plate and extracted three times with solvent system II. The u.v.-absorbing band (section 2) with an $R_{F}$ of 0.82 exhibited 76 to $91 \%$ of the activity of the extract applied to the plate (Table 1). The dry weight-based specific activity of the most purified sample was $1.5 \times 10^{5}$ times higher than that of the original culture supernatant.

Mass spectroscopy (see below) indicated that the active material eluted from the cellulose thin-layer chromatogram was distinguished from neighbouring inactive material by its content of a substance vaporizing at approximately $150^{\circ} \mathrm{C}$ under high vacuum, and so the active extract from the cellulose thin-layer plate was further subjected to distillation under 


\section{Table 1. Dry weights and biological activities of samples from different} stages of purification

\begin{tabular}{|c|c|c|c|c|c|c|c|}
\hline & & & Concer & ation & factor & & \\
\hline & $\left(\mu \mathrm{g} \mathrm{ml}^{-1}\right)^{*}$ & $0 \times$ & $1 x^{*}$ & $2 \times$ & $4 \times$ & $8 \times$ & activity \\
\hline Control & & $11 \cdot 5$ & & & & & \\
\hline Culture supernatant fluid $\ddagger$ & $5580 \cdot 0$ & & $54 \cdot 0$ & - & $\longrightarrow$ & - & 0.00762 \\
\hline Methanolic extract $\ddagger$ & $3590 \cdot 0$ & & $49 \cdot 0$ & - & - & - & 0.0104 \\
\hline Methanol-insoluble fraction & $591 \cdot 0$ & & $16 \cdot 5$ & 一 & - & 一 & \\
\hline Methanol-precipitate fraction & $847 \cdot 0$ & & $16 \cdot 5$ & 一 & - & 一 & \\
\hline Ethanolic eluate from charcoal $\ddagger$ & $35 \cdot 0$ & & $46 \cdot 0$ & $46 \cdot 5$ & $60 \cdot 0$ & $41 \cdot 5$ & 0.986 \\
\hline Charcoal pass-through & $3604 \cdot 0$ & & $19 \cdot 5$ & - & 一 & - & \\
\hline $\begin{array}{l}\text { Extracts from paper } \\
\text { chromatogram: }\end{array}$ & & & & & & & \\
\hline 1 & $0 \cdot 260$ & & $14 \cdot 0$ & $12 \cdot 0$ & $14 \cdot 5$ & $13 \cdot 0$ & \\
\hline $2 \ddagger \S$ & 0.813 & & $21 \cdot 0$ & $40 \cdot 0$ & $41 \cdot 0$ & $37 \cdot 5$ & $11 \cdot 7$ \\
\hline 3 & $9 \cdot 870$ & & $9 \cdot 5$ & $8 \cdot 5$ & $10 \cdot 0$ & $6 \cdot 0$ & \\
\hline Extracts from silica gel plate: & & & & & & & \\
\hline $1 \mathrm{SFq}$ & $0 \cdot 310$ & & $12 \cdot 0$ & $10 \cdot 0$ & $17 \cdot 5$ & $15 \cdot 0$ & \\
\hline 1 REM + T & 0.901 & & $21 \cdot 0$ & $30 \cdot 0$ & $33 \cdot 0$ & $36 \cdot 5$ & $10 \cdot 5$ \\
\hline 2 & 0.597 & & $12 \cdot 0$ & $16 \cdot 0$ & $13 \cdot 5$ & $9 \cdot 5$ & \\
\hline $3 \sharp$ & $0 \cdot 301$ & & $6 \cdot 0$ & $19 \cdot 0$ & $16 \cdot 0$ & $10 \cdot 0$ & \\
\hline Extracts from cellulose plate: & & & & & & & \\
\hline $1 \mathrm{SFI}$ & 0.002 & & $9 \cdot 5$ & $11 \cdot 0$ & $14 \cdot 0$ & $16 \cdot 0$ & \\
\hline 1 REMT & 0.002 & & $14 \cdot 0$ & $12 \cdot 0$ & $18 \cdot 0$ & $17 \cdot 0$ & \\
\hline $2 \ddagger$ & $0 \cdot 011$ & & $24 \cdot 0$ & $27 \cdot 5$ & $31 \cdot 5$ & $20 \cdot 5$ & 1140 \\
\hline 3 & 0.019 & & $14 \cdot 0$ & $14 \cdot 0$ & $13 \cdot 5$ & $11 \cdot 0$ & \\
\hline 4 & $0 \cdot 860$ & & $11 \cdot 5$ & $14 \cdot 0$ & 16.0 & $10 \cdot 0$ & \\
\hline
\end{tabular}

* Values based on dilution of the fraction to that portion of the volume of the original culture supernatant fluid not used for biological assays.

$\dagger$ (Activity of $1 \times$ concentrate - control activity) $\div\left(\mu \mathrm{g}\right.$ dry weight $\left.\mathrm{ml}^{-1}\right)$. Activities are expressed as the percentage of heterocysts with contiguous akinetes.

‡ Fractions used for subsequent purification: activity at each stage of the purification was dependent on the use of an active extract from the previous stage.

$\S$ In other experiments, up to $91 \%$ of the sporulation-stimulatory activity of the combined ethanolic eluate fractions from charcoal was recovered in this fraction.

If Includes sections 4, 5 and 6 from the silica gel thin-layer plate.

If Section 1 of Fig. $1(b)$ and $(c)$ was subdivided into a solvent front zone (SF) and the remainder (REM) of the section.

vacuum at $150{ }^{\circ} \mathrm{C}$. The distillate chromatographed on a cellulose thin-layer plate, developed with solvent system II, as a single u.v.-absorbing band with an $R_{F}$ of 0.81 , exhibited 30 to $52 \%$ of the activity of the original methanolic extract, in SSM, and also stimulated sporulation in a phosphate-containing growth medium (Hirosawa \& Wolk, 1979).

\section{Structural characterization}

The active u.v.-absorbing band extracted from the cellulose thin-layer plate and used for mass spectral analysis was contaminated with material from a band of lower $R_{F}$. Figure $2(a)$ shows a mass spectral 'fragmentogram' of seven fragments $(m / e 41,44,56,96,123,151$ and 265) predominant in the sample. Among them, only the fragments with an $m / e$ ratio of 96 , 123 and 151 were both dominant in the sample containing the sporulation-stimulatory substance and not characteristic of the 'fragmentogram' (Fig. 2b) of the material extracted separately from the neighbouring u.v.-fluorescent band on the cellulose plate. The presence of these fragments was maximal at $150{ }^{\circ} \mathrm{C}$. The mass spectrum of material evaporating into the electron beam at that temperature showed, in addition to the principal molecular ion peak at $m / e 151$, peaks of high intensity at $m / e 123$ and 96 (Fig. 3). As measured with high 

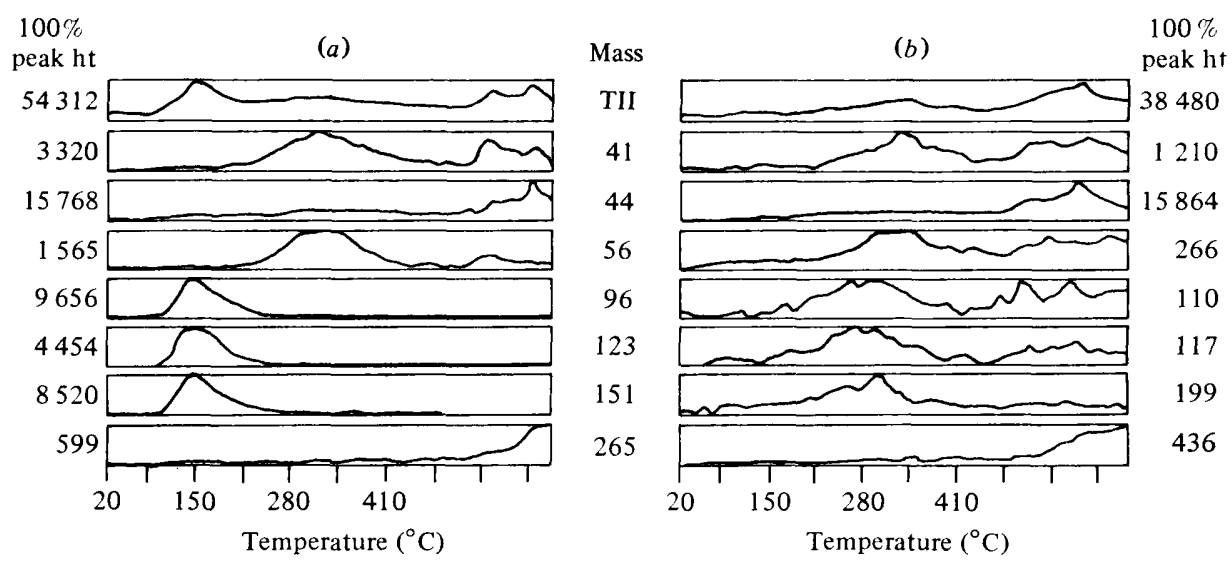

Fig. 2. Mass spectral 'fragmentograms' of $(a)$ the active extract from a cellulose thin-layer chromatogram and $(b)$ an inactive extract of material with slightly lower $R_{F}$. TII refers to the total ion intensity; other lines show the intensity of ions corresponding to a particular $m / e$ value, as a function of temperature.

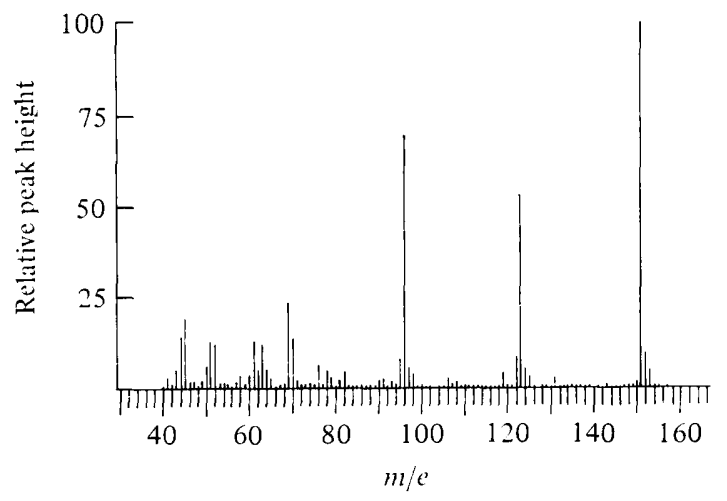

Fig. 3. Mass spectrum of the material evaporating into the electron beam at $150^{\circ} \mathrm{C}$.

resolution, the third of these peaks corresponded to a mass of $96 \cdot 00314$, which is consistent with only one possible structural formula, $\mathrm{C}_{5} \mathrm{H}_{4} \mathrm{~S}$ (see Table 2 ). The only structural formula for the parent ion which is consistent with its mass (151.00931) and with the structure of that fragment is $\mathrm{C}_{7} \mathrm{H}_{5} \mathrm{OSN}$. The fragments of $m / e 123$ and 96 arose by loss of $\mathrm{CO}$ and by additional loss of HCN from the molecular ion (Table 2). The presence of an atom of sulphur in the molecule was indicated also by the high ratios (attributable to the ratio $\left.{ }^{34} \mathrm{~S} /{ }^{32} \mathrm{~S}\right)$ of the heights of the peaks at $m / e+2$ to the heights of the parent $(m / e)$ peaks. The paucity of hydrogen atoms relative to carbon atoms indicated that the molecule contains unsaturated bonds.

A proton magnetic resonance spectrum of $0.5 \mathrm{mg}$ of the vacuum-distilled sporulationstimulatory material showed a complex pattern of peaks in the region $\delta=7 \cdot 19$ to $7 \cdot 29$ p.p.m. (Fig. 4). Peaks at $\delta=1 \cdot 940,2 \cdot 165,7 \cdot 845,7 \cdot 840,7 \cdot 157,5 \cdot 84$ and $5 \cdot 73$ p.p.m. originated from the solvent.

Infrared spectra of $0.5 \mathrm{mg}$ of the vacuum-distilled sporulation-stimulatory material in a disc of $\mathrm{KBr}$ consistently showed peaks at $800,1010,1085,1257,1627,1725,2855,2930$, 2988 and $3429 \mathrm{~cm}^{-1}$ (Fig. 5, top). Although $\mathrm{KBr}$ itself can sometimes show a peak at $3429 \mathrm{~cm}^{-1}$, perhaps due to water absorbed by the salt, a control spectrum of a disc contain- 
Table 2. Molecular weights, measured with high resolution, and possible chemical formulae of the major ions in the mass spectrum of the active material

\begin{tabular}{|c|c|c|c|}
\hline Mol. wt & $\begin{array}{l}\text { Possible chemical } \\
\text { formulae* }\end{array}$ & Mass difference & Loss \\
\hline 151.00931 & $\begin{array}{l}\mathrm{C}_{1} \mathrm{H}_{3} \mathrm{O}_{5} \mathrm{~N}_{4} \\
\mathrm{C}_{2} \mathrm{H}_{7} \mathrm{~S}_{2} \mathrm{~N}_{4} \\
\mathrm{C}_{4} \mathrm{H}_{7} \mathrm{O}_{4} \mathrm{~S}_{1} \\
\mathrm{C}_{5} \mathrm{H}_{3} \mathrm{~S}_{1} \mathrm{~N}_{4} \\
\mathrm{C}_{7} \mathrm{H}_{5} \mathrm{O}_{1} \mathrm{~S}_{1} \mathrm{~N}_{1}\end{array}$ & $\begin{array}{r}-0.00104 \\
-0.00191 \\
0.00281 \\
0.00145 \\
0.00012\end{array}$ & $07.00512(\mathrm{CO})$ \\
\hline $123 \cdot 01418$ & $\begin{array}{l}\mathrm{H}_{3} \mathrm{O}_{4} \mathrm{~N}_{4} \\
\mathrm{C}_{2} \mathrm{H}_{5} \mathrm{O}_{5} \mathrm{~N}_{1} \\
\mathrm{C}_{3} \mathrm{H}_{7} \mathrm{O}_{3} \mathrm{~S}_{1} \\
\mathrm{C}_{6} \mathrm{H}_{5} \mathrm{~S}_{1} \mathrm{~N}_{1}\end{array}$ & $\begin{array}{r}-0.00125 \\
-0.00258 \\
0.00260 \\
0.00009\end{array}$ & $27.99513(\mathrm{CO})$ \\
\hline $96 \cdot 00314$ & $\begin{array}{l}\mathrm{C}_{1} \mathrm{H}_{4} \mathrm{O}_{5} \\
\mathrm{C}_{5} \mathrm{H}_{4} \mathrm{~S}_{\mathrm{I}}\end{array}$ & $\begin{array}{l}-0.00273 \\
-0.00023\end{array}$ & \\
\hline
\end{tabular}

* Permissible tolerance of mass, relative to the measured molecular weight: \pm 0.00300 .

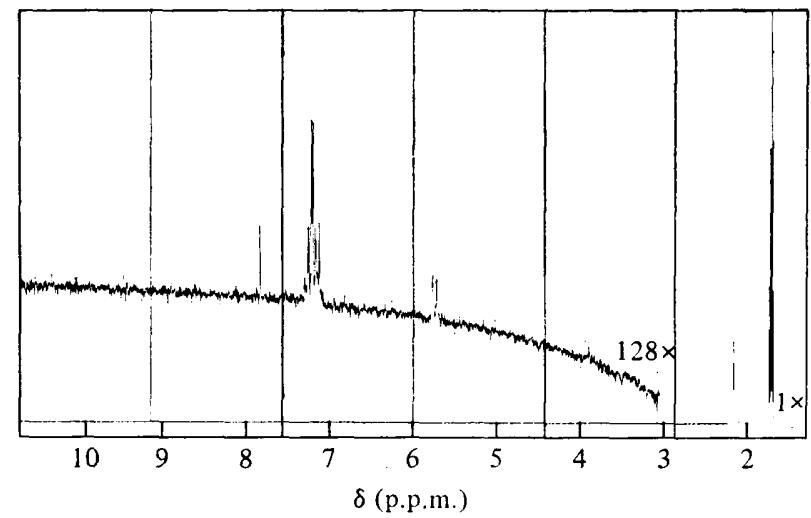

Fig. 4. Proton magnetic resonance spectrum of the vacuum-distilled sporulationstimulatory substance.

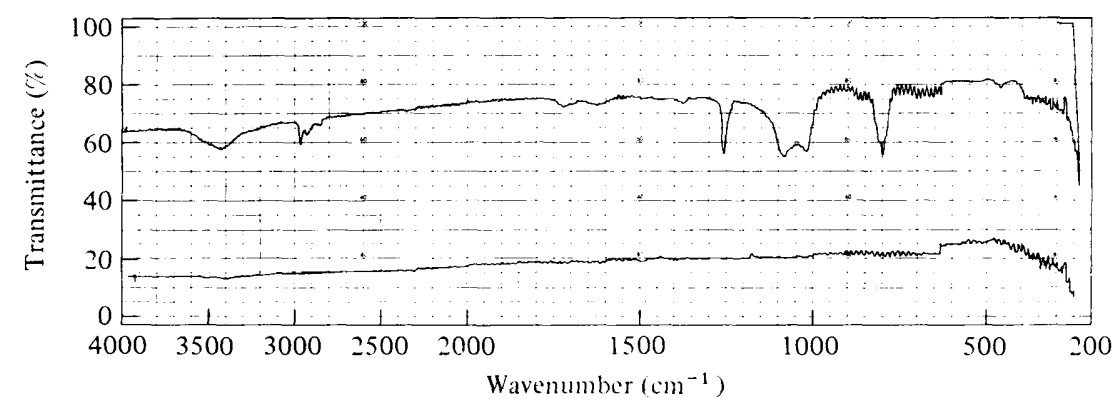

Fig. 5. Infrared spectra of (top) the vacuum-distilled sporulation-stimulatory substance in a $\mathrm{KBr}$ pellet and (bottom, transmittance offset) a $\mathrm{KBr}$ pellet without additional material. 
ing only the same amount of $\mathrm{KBr}$ from the same batch as in the sample disc showed much lower absorption at that wavenumber (Fig. 5, bottom).

The ultraviolet absorption spectrum of the sporulation-stimulatory material dissolved in acetonitrile showed peaks at 242, 247, 253, 263 and $268 \mathrm{~nm}$. However, no useful structural information was derived from these data.

\section{DISCUSSION}

A substance which is capable of stimulating the formation of akinetes has been purified from the centrifugal supernatant fluids of akinete-forming cultures of Cylindrospermum licheniforme. About 50 to $70 \%$ of the total activity was lost during the purification. Significantly, the purified compound alone, even at high concentration, did not stimulate the formation of akinetes as strongly as did the original culture supernatant fluid. Thus, other substances, which may be active by themselves or may potentiate the sporulationstimulatory activity of the isolated substance, must also be present.

The purified substance appeared to be the major single substance responsible for the activity. It has a molecular weight of 151 and was maximally active at less than $0 \cdot 3 \mu \mathrm{M}$. Its molecular weight corresponds to the chemical formula $\mathrm{C}_{7} \mathrm{H}_{5} \mathrm{OSN}$. Production of the fragment $\mathrm{C}_{6} \mathrm{H}_{5} \mathrm{SN}$ by the loss of $\mathrm{CO}$ from the molecular ion cannot be attributed to the presence of an aldehyde group in the molecule, because the absence of aldehydic hydrogen is indicated by the lack of proton magnetic resonance in the region of $\delta=9$ to 10 p.p.m. (Paudler, 1971), and by the absence of absorption in the i.r. spectrum at about 2720 and $2820 \mathrm{~cm}^{-1}$ (Conley, 1972). The composition of the fragment $\mathrm{C}_{5} \mathrm{H}_{4} \mathrm{~S}$ is consistent with the idea that it was produced by the loss of $\mathrm{HCN}$ from the first fragment. The high intensity of the peak at $m / e 96$ in the mass spectrum and the absence of other peaks of comparably high intensity at lower values of $m / e$ indicate that the fragment with $m / e 96$ has a stable ring structure; three such structures ( $a, c$ and $d$ ) are consistent with the chemical formula of that ion.

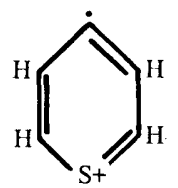

(a)

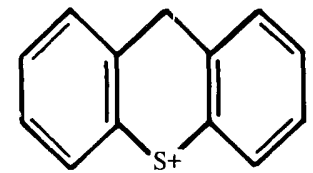

(b)<smiles></smiles>

(c)

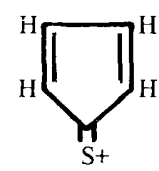

(d)

Ring ( $a$ ) may be excluded because it is structurally so strained that benzene rings at both sides of the ring, as in $(b)$, appear to be required to stabilize the structure, and because the formula of the fragment would require an unligated bond. Structure $(c)$, a thiophene ring with a methylene substituent, may also be excluded because no fragment was observed which corresponded to the thiophene ring itself, and because the formula of the substituted thiophene would also require an unligated bond. The third possibility, a five-membered ring with a thioketone group $(d)$, is consistent with the presence of a strong absorption attributable to $\mathrm{C}=\mathrm{S}$ at $1085 \mathrm{~cm}^{-1}$, and the absence of absorptions attributable to $\mathrm{C}-\mathrm{S}$ and $\mathrm{S}-\mathrm{H}$ at 590 to 700 and at 2550 to $2600 \mathrm{~cm}^{-1}$ in the i.r. spectrum. Peaks attributable to $\mathrm{C}=\mathrm{C}, \mathrm{C}=\mathrm{C}-\mathrm{H}, \mathrm{C}-\mathrm{C}$, and methylene $\mathrm{C}-\mathrm{H}$ bonds were observed at 1627, 2988, 800, and 2855 plus $2930 \mathrm{~cm}^{-1}$, whereas peaks attributable to $-\mathrm{N}=\mathrm{C}=\mathrm{O}$ and $\mathrm{C} \equiv \mathrm{C}$ were not observed.

The absence of resonance peaks at a low p.p.m. range in the proton n.m.r. spectrum together with the complex pattern of peaks in the region of $\delta=7 \cdot 19$ to 7.29 p.p.m. imply that the substance has a highly conjugated ring structure (Paudler, 1971).

A peak at $3429 \mathrm{~cm}^{-1}$ in the i.r. absorption spectrum may be assigned to the $\mathrm{N}-\mathrm{H}$ stretching vibration of a secondary amine or amide. The alternative possibility that the peak cor- 


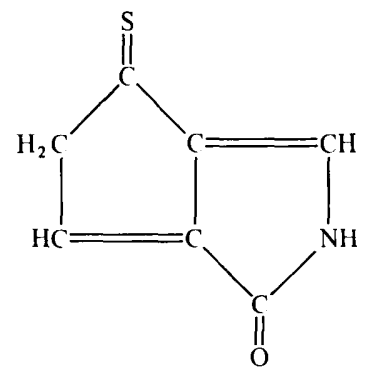

Fig. 6. Approximate structure of the substance which stimulates the formation of akinetes in $C$. licheniforme. The positions of the thioketone group within the left-hand ring, and of the $\mathrm{C}=\mathrm{C}$ double bonds, cannot be determined from the available data.

responds to an $\mathrm{O}-\mathrm{H}$ stretching vibration was eliminated because no absorption attributable to an $\mathrm{O}-\mathrm{H}$ bending vibration was observed in the region of 1300 to $1500 \mathrm{~cm}^{-1}$ or at about $650 \mathrm{~cm}^{-1}$. Because only one peak was detected in the region of $3429 \mathrm{~cm}^{-1}$, the nitrogen cannot be present as a primary amine $\left(-\mathrm{NH}_{2}\right)$. Lack of absorption in the region of 1550 to $1530 \mathrm{~cm}^{-1}$, which would have been attributable to $\mathrm{N}-\mathrm{H}$ bending vibration, suggests that the $\mathrm{N}-\mathrm{H}$ group is a constituent of a cyclic amide. Absorption at $1725 \mathrm{~cm}^{-1}$ supports the possibility that the oxygen atom in the molecule is present in a carbonyl group which is both conjugated and part of an amide group in a five-membered ring (Conley, 1972: see pp. 168, 180). A major peak at $1257 \mathrm{~cm}^{-1}$ is attributable to the amide III band (C-N stretch) of a secondary amide. Taken together, these results provide strong support for the idea that the nitrogen and oxygen in the molecule are present as a secondary amide group in a fivemembered ring. This interpretation accords closely with the mass spectrum provided that the nitrogen atom is not adjacent to group $(d)$, so that $\mathrm{NCH}$ may be lost as a group after (or together with) loss of $\mathrm{CO}$. The structure of the substance is therefore approximately as shown in Fig. 6. The structure must be planar because each of the rings is planar and because the paucity of hydrogens necessitates that at least one of the carbon atoms common to the two rings is double-bonded to another atom of carbon. The second carbon atom common to the two rings cannot therefore be tetrahedral, and so must also be double-bonded. However, the precise positions of the $\mathrm{C}=\mathrm{S}$ and of the $\mathrm{C}=\mathrm{C}$ double bonds cannot yet be assigned. None of the possible structures appears to have been known previously.

Our results with exclusion gel chromatography confirm unpublished experiments by R. W. Fisher and C. P. Wolk. We thank Dr Frank J. Bennis and Mr Bernd Soltmann for assistance with n.m.r. spectroscopy and mass spectrometry, respectively. This work was supported by the U.S. Department of Energy under contract EY-76-C-02-1338.

\section{REFERENCES}

Conley, R. T. (1972). Infrared Spectroscopy, 2nd edn. Boston, Mass.: Allyn and Bacon.

Fisher, R. W. \& Wolk, C. P. (1976). Substance stimulating the differentiation of spores of the blue-green alga Cylindrospermum licheniforme. Nature, London 259, 394-395.

Hirosawa, T. \& Wolk, C. P. (1979). Factors controlling the formation of akinetes adjacent to heterocysts in the cyanobacterium Cylindrospermum licheniforme Kütz. Journal of General Microbiology 114, 423-432.

Paudler, W. W. (1971). Nuclear Magnetic Resonance. Boston, Mass.: Allyn and Bacon.

Piskornik, Z. \& Bandurski, R. S. (1972). Purification and partial characterization of a glucan containing indole-3-acetic acid. Plant Physiology 50, 176-182.
Quisenberg, K. S., Scolman, T. T. \& Nier, A. O. (1956). Atomic mass of $\mathrm{H}^{1}, \mathrm{D}^{2}, \mathrm{C}^{12}$, and $\mathrm{S}^{32}$. Physical Reviews 102, 1071-1075.

ROPER, R. \& MA, T.S. (1957). A new microdistillation technique. Microchemical Journal 1, 248-251.

Schaeffer, P., Miller, J. \& Aubert, J.-P. (1965). Catabolic repression of bacterial sporulation. Proceedings of the National Academy of Sciences of the United States of America 54, 704-711.

Sonenshein, A. L. \& Campbell, K. M. (1978). Control of gene expression during sporulation. In Spores VII, pp. 179-192. Edited by G. Chambliss \& J. C. Vary. Washington, D.C.: American Society for Microbiology. 